\title{
Streptococcus dysgalactiae subspecies dysgalactiae as a cause of urinary tract infection in a diabetic woman: A case report and review of literature
}

\author{
Yashik Bansal, Vibhor Tak, Vijaya Lakshmi Nag \\ Department of Microbiology, All India Institute of Medical Sciences (AIIMS), Jodhpur, Rajasthan, India
}

\begin{abstract}
Summary
Group C Streptococci comprises of Streptococcus dysgalatiae that is further divided into two subspecies, namely $S$. dysgalactiae subspecies equisimilis and $S$. dysgalactiae subspecies dysgalactiae. $S$. dysgalactiae subspecies dysgalactiae is mainly an animal pathogen but few cases of human infections have been described in the literature. A 40 year old patient presented to the hospital with complaints of pain in pelvis and suprapubic area. Urine sample of the patient was subjected to microscopy and culture for isolation
\end{abstract}

Correspondence: Vibhor Tak, Associate Professor, Department of Microbiology, All India Institute of Medical Sciences (AIIMS), Jodhpur, Rajasthan 342005, India.

Tel.: +91.8003991307.

E-mail: vibhor_tak@yahoo.com

Key words: Urinary tract infection, Streptococcus dysgalactiae, Group C Streptococci, zoonotic disease.

Contributions: V.T. and Y.B. were involved in conception and design. Y.B., V.T. and V.L.N. conducted the work and analyzed the data. Y.B. prepared the first draft of the manuscript. V.T. and V.L.N. reviewed and made corrections to the manuscript. All authors have read, approved the final draft and account for all aspect of the work.

Conflict of interest: The authors declare no conflict of interest.

Funding: None.

Ethical considerations: Informed consent was taken from the patient regarding the use of anonymised data for publishing that does not identify the patient. The study conforms to ethical guidelines for biomedical research on human subjects as given by the Central Ethics Committee on Human Research (CECHR) of Indian Council of Medical Research (ICMR), New Delhi in 2006 and as given in the 'Declaration of Helsinki' 1975 as revised in 2013.

Received for publication: 12 June 2020.

Revision received: 18 August 2020.

Accepted for publication: 19 September 2020.

${ }^{\circ}$ Copyright: the Author(s), 2020

Licensee PAGEPress, Italy

Microbiologia Medica 2020; 35:9176

doi:10.4081/mm.2020.9176

This article is distributed under the terms of the Creative Commons Attribution Noncommercial License (by-nc 4.0) which permits any noncommercial use, distribution, and reproduction in any medium, provided the original author(s) and source are credited. and identification of the etiological agent. $S$. dysgalactiae subspecies dysgalactiae was identified from the clinical specimen of the patient by conventional and automated methods. The patient was successfully treated with third generation cephalosporin. With newer or rarely reported pathogens causing human diseases and increase in number of immunocompromised individuals in the population, the pathogenic potential of such isolates should not be undermined and a careful correlation with the clinical profile should help guide a clinician in optimum treatment of the patient.

\section{Introduction}

Group C Streptococci comprises of Streptococcus dysgalatiae that is further divided into two subspecies, namely $S$. dysgalactiae subsp. equisimilis (SDSE) and $S$. dysgalactiae subsp. dysgalactiae (SDSD) (1). SDSE exhibits distinct Lancefield group antigens $\mathrm{C}$ and $G$ whereas SDSD exhibits antigen C and L (2). SDSD is mainly a pathogen of animals but human infections have been reported on rare occasions in the literature. A literature search on PubMed using the search term "((Streptococcus dysgalactiae) AND (subspecies dysgalactiae)) NOT (subspecies equisimilis)" helped us identify five reports of SDSD infections in humans (1-5). Here, we present a rare case of a patient that was diagnosed with SDSD urinary tract infection (UTI) and treated for the same at our hospital.

\section{Case description}

A 40-years-old female visited the out patient department of our tertiary care center with complaints of pain in pelvic and suprapubic region, over the past few weeks, which was insidious in onset, not associated with vaginal discharge. The patient also experienced occasional episodes of pain in abdomen. Her menstrual history was insignificant and ruled out pregnancy. The patient was married, having kids and had no history of contact with multiple partners. There was no past medical history or history of instrumentation or surgical intervention. On examination, the patient reported slight tenderness in the suprapubic area but there was no guarding or rigidity in the abdomen. No organomegaly was detected upon physical examination. Her body temperature was $38.3^{\circ} \mathrm{C}$, total leucocyte count was elevated $(17300 / \mu \mathrm{L})$.

The radiological investigations included Ultrasonography (USG) of the abdomen and X-ray of the pelvis and lumbar spine. While the X-rays were normal, there was evidence of hepatomegaly with coarsened texture of liver parenchyma and periportal echogenicity around the left portal vein. Kidneys and urinary tract showed no abnormality on USG. Liver function tests were 
performed and all parameters were within normal range. Hemogram was normal but the patient was diabetic with a fasting blood sugar level of $9.56 \mathrm{mmol} / \mathrm{L}$ (diabetic status not known previously to the patient). PAP (Papanicolaou) smear sent to the pathology laboratory for cytological examination was normal.

Patient's urine sample was collected in a sterile, screw capped universal container and transported to the Microbiology laboratory within 15 minutes at room temperature in a sample transport container. On microscopic examination, there were 4-5 pus cells per high power field (40x) that confirmed the presence of pyuria. Ketones, sugar and protein not detected on routine examination. Urine culture was done on Chromogenic UTI agar (HiCHROM Media, HiMedia Laboratories, India) and was incubated aerobically at $37^{\circ} \mathrm{C}$. Culture showed a confluent growth of large, opaque, colourless colonies with slight blue tint after overnight incubation. The colony count of the bacterial colonies was $>10^{5}$ per $\mathrm{ml}$ of urine sample.

An isolated colony was picked up and catalase test was performed using 3\% $\mathrm{H}_{2} \mathrm{O}_{2}$ which was negative. Gram's stained smear prepared from a colony showed Gram positive cocci (GPC) in short chains. A subculture was performed on $5 \%$ sheep blood agar (HiMedia Laboratories, India) and Chocolate agar (HiMedia Laboratories, India). A disc of bacitracin and optochin were placed on the blood agar plate. Large, alpha-hemolytic colonies were demonstrated on blood agar after overnight incubation at $37^{\circ} \mathrm{C}$ under aerobic conditions and no zone of inhibition was present around the bacitracin and optochin discs. Further, on the day identification was done using an automated microbial identification system (MicroScan WalkAway 96 Plus, Beckman Coulter Inc, CA, USA). Also, phenotypic identification tests viz. bile solubility and Christie-Atkins-MunchPeterson (CAMP) test were also put up to aid in identification.

Bile solubility and CAMP tests were negative. The isolate was identified as $S$. dysgalactiae subsp. dysgalactiae by the automated system. The patient was treated with a trial of oral cefexime $400 \mathrm{mg}$ /day for 10 days. Repeat urine culture was negative after four weeks and clinical resolution of the patient's illness was achieved.

\section{Discussion}

S. dysgalactiae was divided into two subsp. i.e. SDSE and SDSD in 1996 by Vandamme on the basis of their host preferences (6). SDSE is mainly a human pathogen whereas SDSD primarily infects animals (1), is known to cause bovine mastitis and has been isolated from milk (7). Few cases of SDSD associated human infections have been described before. A review of available literature is presented in Table 1.

In all the cases, the typical patient profile was a middle aged or elderly patient with history of contact with animal, and an immunocompromised state as a result of past medical condition or drugs. The zoonotic potential of SDSD human infections has previously been demonstrated by Alves-Borroco et al. (7) using human respiratory cells and adult zebrafish animal model. The study showed that SDSD was able to internalize and cause infection in both human cells in vitro as well as zebrafish in vivo. Rodrigues et al. (8) had previously shown that SDSD isolates from bovine milk udders containing the phage encoded GAS genes were capable of infecting human keratinocytes in vitro.

Owing to the need of faster diagnosis, many laboratories use newer culture media formulations such as chromogenic media, followed by identification and Antimicrobial Susceptibility Testing (AST) by automated methods. However, it is essential to perform haemolysis testing on blood agar for Streptococcus spp. isolates. The susceptibility to benzylpenicillin on AST is used to predict the susceptibility of the isolate to penicillins and other beta lactam antibiotics including cephalosporins (9). As the non susceptible isolates are rare, patients are usually treated with a trial of penicillin or cephalosporin (9). The use of these antibiotics in animal meat and dairy industry raises concerns of anti microbial resistance (10).

The western part of Rajasthan is a desert area that largely relies on tourism and agricultural and livestock activities for sustaining majority of the households (11). Zoonotic diseases such as brucellosis are prevalent in this area owing to close contact with animals, consumption of unpasteurized or unboiled milk and dairy products (12). Although we could not reliably ascertain the history of close contact in the patient, the acquisition of infection from an infected animal could not be ruled out owing to agricultural background and her eating habits. Lastly, the lack of advanced diagnostic modalities in majority of the laboratories in a developing country like ours makes the management of rare entities like these a challenge.

\section{Conclusions}

With newer or rarely reported pathogens causing human diseases and increase in number of immunocompromised individuals in the population, the pathogenic potential of such

Table 1. Review of the literature.

\begin{tabular}{|c|c|c|c|c|c|}
\hline Year & Authors & Patient age/Gender & Site & History/Risk factors & Outcome \\
\hline 2009 & Koh et al. ${ }^{4}$ & 48 years/Female & Cellulitis of right arm and breast & Trauma from fin of a fish & Recovered \\
\hline 2012 & Park et al. ${ }^{1}$ & 61 years/Male & $\begin{array}{l}\text { Right knee with prosthetic joint } \\
\text { infection }\end{array}$ & $\begin{array}{l}\text { Surgery. } \\
\text { No documented history } \\
\text { suggesting zoonoses }\end{array}$ & Recovered \\
\hline 2014 & Jordal et al.3 & 65 years/Male & $\begin{array}{l}\text { Infective endocarditis with septic } \\
\text { embolization to brain and left } \\
\text { shoulder }\end{array}$ & $\begin{array}{l}\text { Malignant tumor of rectum. } \\
\text { No documented history } \\
\text { suggesting zoonoses }\end{array}$ & Recovered \\
\hline 2018 & Chennapragada et al. ${ }^{2}$ & 49 years/Female & $\begin{array}{l}\text { Left lower limb cellulitis } \\
\text { and bacteremia }\end{array}$ & $\begin{array}{l}\text { No clear history identified. } \\
\text { Possible exposure to a } \\
\text { domesticated dog }\end{array}$ & Improved \\
\hline 2019 & Koh et al. ${ }^{5}$ & $\begin{array}{l}48 \text { years/Female* } \\
\text { Two more female patients }\end{array}$ & $\begin{array}{l}\text { Ascending cellulitis in all three } \\
\text { patients with breast cancer }\end{array}$ & $\begin{array}{l}\text { One patient had trauma from fish. } \\
\text { One patient was a chicken handler. } \\
\text { No information on third patient }\end{array}$ & No information available \\
\hline
\end{tabular}

*Same patient as reported by Park et al in 2012 (first study in this table). 
zoonotic isolates should not be undermined and a careful correlation with the clinical profile should help guide a clinician in optimum treatment of the patient. A collaborative network of emerging institutes with a reference institute having advanced diagnostic facilities is the need of the hour in developing countries.

\section{References}

1. Park MJ, Eun IS, Jung CY, et al. Streptococcus dysgalactiae subspecies dysgalactiae infection after total knee arthroplasty: a case report. Knee Surg Relat Res 2012;24:120-3.

2. Chennapragada SS, Ramphul K, Barnett BJ, et al. A Rare Case of Streptococcus dysgalactiae Subsp. Dysgalactiae Human Zoonotic Infection. Cureus 2018;10:e2901.

3. Jordal S, Glambek M, Oppegaard O, et al. New tricks from an old cow: infective endocarditis caused by Streptococcus dysgalactiae subsp. dysgalactiae. J Clin Microbiol 2015;53:731-4.

4. Koh TH, Sng LH, Yuen SM, et al. Streptococcal cellulitis following preparation of fresh raw seafood. Zoonoses Public Health 2009;56:206-8.

5. Koh TH, Binte Abdul Rahman N, Sessions OM. Comparative genomic analysis of Streptococcus dysgalactiae subspecies dysgalactiae, an occasional cause of zoonotic infection. Pathology 2020;52:262-6.

6. Vandamme P, Pot B, Falsen E, et al. Taxonomic study of lancefield streptococcal groups C, G, and L (Streptococcus dysgalactiae) and proposal of S. dysgalactiae subsp. equisimilis subsp. nov. Int J Syst Bacteriol 1996;46:774-81.

7. Alves-Barroco C, Roma-Rodrigues C, Raposo LR, et al. Streptococcus dysgalactiae subsp. dysgalactiae isolated from milk of the bovine udder as emerging pathogens: In vitro and in vivo infection of human cells and zebrafish as biological models. Microbiologyopen 2019;8:e00623.

8. Roma-Rodrigues C, Alves-Barroco C, Raposo LR, et al. Infection of human keratinocytes by Streptococcus dysgalactiae subspecies dysgalactiae isolated from milk of the bovine udder. Microbes Infect 2016;18:290-3.

9. European Committee on Antimicrobial Susceptibility Testing (EUCAST)

https://www.eucast.org/fileadmin/src/media/PDFs/EUCAST_fil es/Breakpoint_tables/v_10.0_Breakpoint_Tables.pdf (Last accessed August 17, 2020).

10. Dadgostar P. Antimicrobial Resistance: Implications and Costs. Infect Drug Resist 2019;12:3903-10.

11. Patidar M, Patel AK, Misra AK, et al. Improving Livelihood of Farmers through Livestock Interventions in Nagaur District of Rajasthan. Central Arid Zone Research Institute (CAZRI), Jodhpur. 2014: 56p. Available at: http://www.cazri.res.in/ publications/improv_livestock.pdf. (Accessed on 17th April 2020).

12. Bansal Y, Aggarwal A, Gadepalli R, et al. Seroprevalence of brucellosis in Western Rajasthan: A study from a tertiary care centre. Indian J Med Microbiol 2019;37:426-32. 